\title{
NOTAS SOBRE LA PRUEBA DEL DAÑO MORAL EN LA RESPONSABILIDAD CIVIL
}

\author{
Jorge Femenías Salas* \\ Pontificia Universidad Católica de Chile, Chile \\ jafemeni@uc.cl
}

RESUMEN: El trabajo que presentamos, aborda un tema que demuestra -a nuestro juicio- un especial interés por ser uno de aquellos institutos de la responsabilidad civil que menos desarrollo dogmático han presentado. En efecto, salvo particulares excepciones de algunos especialistas, todos los autores y comentaristas del derecho civil, han descuidado profundizar y desarrollar a cabalidad, una esfera que se juzga sustancial en el universo de la responsabilidad civil, como lo es, la cuestión de la prueba del dańo moral. Así, por diversos motivos que pretendemos exponer en este trabajo -derivados principalmente de la concepción que se tiene del dańo moral- la cuestión de la prueba del menoscabo no patrimonial, no ha sido estudiada en profundidad, dejando -como alguna vez se dijo- un sensible vacío en la materia, tanto más cuanto, se trata de uno de los tópicos fundamentales al momento de llevar a la praxis jurídica las teorizaciones que sobre el particular se han elaborado.

Palabras clave: daño moral, carga de la prueba, avaluación de perjuicios.

ABSTRACT: The work we present deals with a matter which we deem of special interest, as it refers to one of the civil liabilities institutions least treated. In fact, save for certain exceptions from some specialists, all of the civil law authors and commentators have failed to develop thoroughly and in dept, an issue which is crucial in civil liability, i.e. the issue of burden of proof of the non monetary damages. As a result, due to reasons which we shall explain herein under, which mainly refer to the understanding of non monetary damages, the question of evidencing non-monetary aspects of the specific harm, has not been studied in depth. Consequently, as it has been noted, there is an evident void in this matter, more so, as it is considered fundamental in bringing into the legal practice those theories in place.

Keywords: non monetary damage, burden of proof, quantification of damages.

Doctor (C) en Derecho Pontificia Universidad Católica de Chile. Magíster en Ciencia Jurídica, Pontificia Universidad Católica de Chile. Profesor de Derecho Civil, Pontificia Universidad Católica de Chile. Abogado Asociado en Philippi Yrarrázaval Pulido \& Brunner. 


\section{PROEMIO}

Sobre responsabilidad civil se ha escrito bastante durante los últimos lustros en Chile1. Algunos autores nos han presentado sendos tratados ${ }^{2}$ y otros con mejor o peor fortuna han publicado diversas monografías y artículos especializados en torno a los diversos institutos que comprende la materia.

Así, se configuró una "cultura” jurídica de la responsabilidad, en la cual profesores, investigadores y estudiosos del derecho común se han dedicado a desarrollar una materia que -como tantas otras en el derecho privado chileno- habían quedado de modé en el código civil. ${ }^{3}$

Pero curiosamente, salvo particulares excepciones de algunos especialistas ${ }^{4}$, todos los autores y comentaristas del derecho civil han descuidado profundizar y desarrollar a cabalidad una esfera que se juzga sustancial en el universo de la responsabilidad civil, como lo es, la cuestión de la prueba del daño moral.

En efecto, por diversos motivos que pretendemos exponer en este trabajo -derivados principalmente de la concepción que se tiene del daño moral- la cuestión de la prueba del menoscabo no patrimonial, no ha sido estudiada en profundidad, dejando -como alguna vez se dijo- un sensible vacío en la materia, tanto más cuanto, se trata de uno de los tópicos fundamentales al momento de llevar a la praxis jurídica las teorizaciones que sobre el particular se han elaborado.

Ahora, si se piensa que el requisito del daño se configura en un elemento esencial de la responsabilidad civil, al punto que sería el distintivo fundamental, entre la responsabilidad civil, la responsabilidad penal, y la responsabilidad moral ${ }^{5}$, resulta preocupante que la doctrina no haya asistido a los sentenciadores en dilucidar los puntos más conflictivos a la hora de hacer realidad las indemnizaciones por daño moral y en consecuencia no haberse ocupado de desarrollar el problema de su avaluación y prueba.

En este mismo estado de cosas, resulta también evidente - de una somera mirada a la jurisprudencia nacional y comparada- que la solicitud de una indemnización por daño moral, constituye las más de las veces, una de las partidas sustanciales en las demandas por indemnización de perjuicios, tanto en sede extracontractual, como contractual.

\footnotetext{
Por todos: Domínguez Hidalgo, Carmen. El daño Moral. Santiago, Chile: Editorial Jurídica de Chile, 2002.

Véase Barros Bourie, Enrique. Tratado de Responsabilidad Extracontractual. Santiago, Chile: Editorial Jurídica de Chile, 2006. Domínguez Hidalgo, Carmen, op. cit. (n. 1), p. 29.

Ibid., p. 68 y ss.

Mazeaud, Henri, et al. Tratado teórico y práctico de la responsabilidad civil delictual y contractual. Traducción de la $5^{\circ}$ edición francesa por Santiago Sentís Melendo. Buenos Aires, Argentina: Ediciones Jurídicas Europa-América, 1977, p. 293.
} 
De manera que resulta imperativo lograr un adecuado análisis de la prueba del daño moral rendida en los procesos sobre indemnización de perjuicios por responsabilidad civil, ya que, de alguna manera - por modesta que pueda ser- constituye una contribución para evitar los excesos que los países más desarrollados en la materia han experimentado. ${ }^{6}$

En este escenario pretendemos desarrollar el trabajo que se presenta, en torno al tema de la prueba del dańo moral, ofreciendo en panorámica el estado actual de la materia y la evolución que experimentó tanto a nivel jurisprudencial como en la doctrina nacional.

Así, abordaremos de manera sumaria el concepto del daño moral, en tanto ello influye directamente sobre la acreditación de éste ${ }^{7}$, avanzando hacia el estudio de la prueba del menoscabo extrapatrimonial en el proceso, revisando las diversas tendencias jurisprudenciales y doctrinarias sobre el particular, para finalizar mediante la exposición de las conclusiones a que es posible arribar de conformidad al estado actual del arte.

\section{EL DAÑO MORAL: APROXIMACIÓN A UN CONCEPTO DEL PERJUICIO NO PATRIMONIAL}

No siendo el objeto de este trabajo -ni posible en tan pocas líneas- llevar a cabo un desarrollo acabado de la noción de daño moral, en tanto como se ha dicho, "No es exagerado afirmar que la determinación del concepto de daño moral es uno de los problemas más complejos de toda la responsabilidad civil'8, es menester en cualquier caso esbozar sintéticamente los postulados que sobre el particular coexisten actualmente en el ordenamiento jurídico.

Valga entonces la prevención, de tratarse este apartado sólo de una breve exposición de las diversas tesis que sobre la materia se sostienen, cuya función será servir de "puerta de entrada" a la cuestión de la prueba del daño moral, por cuanto, como se expresará, la concepción que del mismo se tenga, redunda directa e ineludiblemente en el problema de la prueba del instituto. ${ }^{9}$

\section{I. CONCEPCIONES TRADICIONALES DE DAÑO MORAL}

Sin hacernos cargo de la problemática que presenta precisar la sola definición de "daño moral", podemos afirmar que existen tantas concepciones del mismo propuestas por la doctrina al punto de abarcar todo el espectro imaginable. ${ }^{10}$

\footnotetext{
Sobre esto, véase Domínguez Hidalgo, Carmen, op. cit. (n. 1), p. 507 y ss.

Rodríguez Grez, Pablo. Responsabilidad Extracontractual. Santiago, Chile: Editorial Jurídica de Chile, 1999, p. 257.

Domínguez Hidalgo, Carmen, op. cit. (n. 1 ), p. 43.

Aedo Barrena, Cristian. "El daño moral: Concepto, prueba y valoración en la doctrina y jurisprudencia Chilena", en: Revista de Ciencias Jurídicas de la Universidad Católica del Norte, Tomo IV, Antofagasta, 2005, p. 121

Domínguez Hidalgo, Carmen, op. cit. (n. 1), p. 46.
}

10 
Por ello, apartándose de todas las sistematizaciones que sobre la noción de daño moral han hecho los autores, diremos simplemente que existen -con sus variaciones y matices- al menos cuatro corrientes tradicionales sobre el particular, las cuales son, a saber:

2.1.1. La concepción del daño moral como Pretium Doloris: Es quizá ésta, la más usual y arraigada concepción de daño moral que se tenga en nuestro derecho de daños. Esta se refiere a lo que los alemanes denominan desde antiguo Schmerzengeld o "daño por el dolor". 1

Los autores que siguen esta concepción, identifican el daño moral con las "aflicciones", "pesares", "molestias" y sufrimientos que experimenta un individuo en su esfera psíquica, a causa de la comisión de un hecho ilícito. ${ }^{12}$

De igual forma esta es la noción que ha recogido mayoritariamente nuestra jurispruden$\operatorname{cia}^{13}$.

2.1.2. El daño moral como todo perjuicio cuyo objeto no es un interés patrimonial: Nos señala Domínguez Hidalgo que:

"Fiel exponente de esta forma de definir el daño no patrimonial es [De Cupis], para el cual éste no puede ser definido más que en contraposición al daño patrimonial, puesto que ambos perjuicios conforman el daño privado (...) Daño no patrimonial es en consonancia con el valor negativo de su misma expresión literal, todo daño privado que no puede comprenderse en el daño patrimonial por tener por objeto un interés no patrimonial, o sea, que guarda relación a un bien no patrimonial'. ${ }^{14}$

2.1.3. El daño moral como lesión a simples intereses: Esta visión ha sido sostenida en Chile por José Luis Diez Schwerter, quién ha señalado, a propósito de sus estudios sobre la jurisprudencia nacional en la materia, que: "Todo lo expuesto nos permite concluir que la jurisprudencia nacional concibe el daño como todo menoscabo, detrimento, lesión, molestia o perturbación a un simple interés del que sea titular una persona o de la situación de hecho en que este se encuentre". ${ }^{5}$

El autor entiende por interés, todo aquello que sea útil, aquellas cosas que no son susceptibles de avaluación pecuniaria, pero que sean de utilidad para un sujeto, que le presten un servicio, o bien satisfagan una necesidad o simplemente rechacen un dolor. ${ }^{16}$

11 Barros Bourie, Enrique, op. cit. (n. 2), p. 287.

12 Véase Alessandri Rodríguez, Arturo. Responsabilidad civil extracontractual en el Derecho Civil Chileno. Tomo I -2da ediciónSantiago, Chile: Editorial Jurídica Conosur, 1998, p. 249.

13 RDJ., T.LXVI., secc. 4ª 1969 , páginas 21 y ss; RDJ, T. XXXVIII, secc. 2a $2^{\text {a }} 1941$, p. 239 y ss; RDJ, T. LXXVI, secc. $4^{\text {a }}$, p. 125

14 Domínguez Hidalgo, Carmen, op. cit. (n. 1), p. 52.

15 Diez Schwerter, José Luis. El Daño Extracontractual. Jurisprudencia y doctrina -1a edición- Santiago, Chile: Editorial Jurídica de Chile, 1997, pp. 23 y ss.

16 Ibid., p. 25. 
2.1.4. El daño moral como lesión a intereses jurídicamente tutelados: Finalmente, existe una posición que toma en consideración no el carácter no patrimonial del interés lesionado, sino más bien que fija la mirada en el hecho de que el ilícito afecta un bien no patrimonial o un interés moral que ha sido reconocido por el ordenamiento jurídico.

En palabras de Zanonni que "La lesión afecte una facultad de actuar que impide o frustra la satisfacción o goce de intereses no patrimoniales reconocidos a la victima del evento dañoso por el ordenamiento juridico". 17

Digamos finalmente - para efectos de lo que a nuestro estudio interesa- que existen a lo menos cuatro concepciones de daño moral y que la tesis que se adopte en la materia, será decisiva al momento de resolver problemas como la evaluación del daño moral, la posibilidad de que las personas jurídicas puedan sufrir daño moral, y especialmente el asunto de la prueba del perjuicio no patrimonial, cuestión que pasamos a analizar a continuación.

\section{LA PRUEBA DEL DAÑO MORAL: EXPOSICIÓN DE UNA TAREA PENDIENTE}

\section{I Estado actual de la cuestión}

Como punto de partida, podemos afirmar -sin temor a equivocarnos- que en materia de prueba del daño moral, la cuestión no es pacífica y tal como ocurre con otros institutos que forman parte de la responsabilidad civil (verbigracia, como lo es el problema de su denominación, la precisión del concepto de daño moral, la avaluación de los perjuicios no patrimoniales, etcétera) no existe una única opinión que resuelva el tema.

Pero aquí hay todavía una especial particularidad, por cuanto se han extrapolado con notable entusiasmo los postulados contradictorios de la doctrina y jurisprudencia.

En efecto, es posible percibir que la doctrina en general se encuentra conteste en una máxima que debe regir el asunto, "el daño moral debe ser acreditado siempre"18 y la jurisprudencia por el contrario ha sido contundente en afirmar que dada la particular naturaleza de éste, el perjuicio no patrimonial no puede ser objeto de prueba, o en el mejor de los casos debe ser presumido. ${ }^{19}$

Frente a esta realidad, no menor resulta el dato de que en derecho comparado, particularmente en los ordenamientos jurídicos vecinos, el desarrollo de la materia ha seguido igual suerte.

17 Zannoni, Eduardo. El daño en la responsabilidad civil. Buenos Aires, Argentina: Astrea, 1978, p. 290.

18 Resulta ilustrativa al respecto la nota al pie de página (376) en: Barros Bourie, Enrique, op. cit. (n. 2), p. 332.

19 Domínguez Hidalgo, Carmen, op. cit. (n. 1), p. 682 
En efecto, en países como Argentina o México la doctrina ha sido uniforme -al igual que la nuestra- en señalar que el daño moral debe acreditarse ${ }^{20}$, mientras que la jurisprudencia ha tendido a invertir el peso de la prueba, bastando con la sola acreditación de la ocurrencia de un hecho que ha causado daño a otro que tenga la entidad de causar un daño moral, para que este se presuma. ${ }^{21}$

En México - por ejemplo- se ha impuesto en la jurisprudencia la tesis de la comprobación objetiva del daño moral y no la subjetiva, lo cual implica que basta la demostración de la relación jurídica que vincula al sujeto activo con el agente pasivo o agraviado y la existencia de un hecho u omisión ilícitos que lesione uno o varios de los bienes que tutela la figura. Entonces, no se requiere la justificación de la existencia efectiva, ni la extensión o gravedad del daño. ${ }^{22}$

En igual sentido se manifiesta en Argentina Juan Carlos Rezzonico, quien expresa que lo único que sería necesario acreditar en los procesos en que se solicite esta partida, es "El sólo hecho de la acción antijuridica y la titularidad del derecho accionante" 23 . Así también se han pronunciado Mosset Iturraspe y Novellino, quienes han dicho que el daño se puede presumir o inferir en los casos que éste surja notorio de los hechos: "Son los hechos los que hablan y dicen el daño. La muerte del padre, del hijo o del esposo, la que evidencia el daño moral-dolor"24. Con ello, se adopta un criterio muy similar al que ha seguido nuestra jurisprudencia, como se expondrá a continuación.

3.1.1 Comentarios a la corriente jurisprudencial sobre la prueba del daño moral: Nada puede resultar más gráfico e ilustrativo para comprender la tesis de nuestra jurisprudencia, denominada in re ipsa, que tomar como referencia algunos fallos de los Tribunales Superiores de Justicia que dejan de manifiesto la tendencia que siguen sobre la materia.

En este escenario, la Excelentísima Corte Suprema de Justicia, ha señalado:

"Una de las razones que justifican en derecho la indemnización por el daño moral es el efecto de la disminución de la capacidad para el trabajo, la depresión de salud o de las energías, fenómenos naturales y ordinarios que, por ello, no necesitan ser especialmente probados, ya que la comprobación de su realidad va incluida en la existencia misma de la desgracia, que para el demandante pariente cercano de la victima importa el delito o cuasi delito cometido en la persona de ésta". ${ }^{25}$

20 Pizarro, Ramón. Daño moral. Prevención. Reparación. Punición-1a edición- Buenos Aires, Argentina: Hammurabi, 2000, p. 532.

21 Rodríguez Curutchet, Juan Pablo. La evaluación y prueba del daño moral en la jurisprudencia Nacional. Tesis (Licenciado en Derecho), Santiago, Chile: Pontificia Universidad Católica de Chile, 2007, p. 125.

22 Pérez Fuentes, Gisela. "El derecho de daños en México", en: Revista Anales de Derecho UC, Temas de responsabilidad Civil, vol. 1, Santiago, Chile, 2006, p. 217

23 Citado por Rodríguez Curutchet, Juan Pablo, op. cit. (n. 21), p. 122.

24 Mosset Iturraspe, Jorge y Novellino, Norberto. Derecho de Daños. La prueba en el proceso de daños. Buenos Aires, Argentina: Ediciones La Rocca, 1996, p. 57.

25 RDJ, T. XLII, secc. $1^{\text {a }}$, p. 392. 
Igualmente González Vergara y Cárdenas Villareal, comentan un fallo que señala:

"En palabras de nuestras cortes el daño moral es de indole netamente subjetiva y su fundamento se centra en la propia naturaleza afectiva del ser humano, de manera que puede decirse que tal daño se produce siempre en un hecho externo que afecta la integridad moral del individuo y por lo tanto la apreciación de éste debe considerarse entregada al juez, pues dada su indole es inconcuso que no puede ni requiere ser acreditado". ${ }^{26}$

De la sola lectura de la sentencia y comentario anteriormente transcritos, se colige con facilidad que nuestra jurisprudencia ha excluido la exigencia probatoria del perjuicio moral. Y así, en ambos casos citados, se ha razonado en torno al concepto de daño moral como sinónimo de pretium doloris.

Lógicamente, analizando desde esta perspectiva el problema, los jueces tenderán a excluir la exigencia probatoria del daño moral, por cuanto estiman, que la dificultad que entrañaría la prueba del mismo haría imposible obtener una indemnización por esta partida para el afectado, ya que resultaría una quimera intentar acreditar el dolor experimentado, o el pesar o malestar que se ha padecido.

Pero el yerro en que se incurre, al adoptar un concepto muy restrictivo de daño moral, es pretender que la prueba del mismo necesariamente debe producirse mediante medios probatorios directos. Ello importaría, "conducir a la imposibilidad de la reparación moral, por ausencia de prueba" 27 . Muy por el contrario, resulta evidente que concebido el daño moral como pretium doloris, los medios más eficaces para la producción de la prueba del perjuicio extrapatrimonial, serán aquellos de carácter indirecto, particularmente la prueba por presunciones o bien los peritajes de los expertos.

Ahora, ello en ningún caso podrá permitir la arbitrariedad del sentenciador al punto de establecer una ficción de daño moral, al contrario éste, para llevar a cabo el razonamiento lógico que importa la presunción como medio probatorio, deberá obtener por parte de la víctima, todos los antecedentes que le permitan deducir - y no suponer - la existencia efectiva del daño en cuestión. $^{28}$

Como vemos, la posición que se adopte en torno al concepto de daño moral -en este caso, la de pretium doloris-, influirá en forma decisiva, -al igual que en la evaluación del mismo- en la esfera probatoria del instituto.

\footnotetext{
26 González Vergara, Paulina y Cárdenas Villareal, Hugo. Sobre la prueba de la existencia del daño moral. En: Jornadas Chilenas de Derecho Civil: Estudios de derecho civil II: código civil y principios generales : nuevos problemas, nuevas soluciones. Santiago, Chile: Lexis Nexis, 2007, p. 255.

27 Ochoa Olivera, Salvador. La demanda por daño moral. Atizapán de Zaragoza, España: Montealto Editores, 1999 , p. 87.

28 Aedo Barrena, Cristian. Responsabilidad Extracontractual. Santiago, Chile: Librotecnia, 2006, p. 516.
} 
Sin perjuicio de lo señalado en precedencia, existe también una variable de la vertiente jurisprudencial anterior, que ha ido aceptando, la categoría -ya advertida por la doctrina- de daño moral como violación a un interés jurídicamente tutelado. ${ }^{29}$

Y resulta interesante señalar, que a pesar de lo diverso que resulta concebir el perjuicio no patrimonial, según una u otra forma, los tribunales han arribado a la misma conclusión en lo relativo a la prueba del daño moral con muy similares fundamentaciones, estimando que el mismo no requiere ser acreditado.

A estos efectos, juzgamos oportuno transcribir un fallo que establece que daño moral será

“(...) La lesión o agravio efectuado culpable o dolosamente, de un derecho subjetivo de carácter inmaterial o inherente a la persona humana y que es imputable a otro hombre (...) Se sigue de este concepto, como consecuencia necesaria, que la demostración de la transgresión o agravio del derecho subjetivo importa, al mismo tiempo, la prueba de la existencia del daño moral. Por consiguiente, en el concepto y naturaleza del daño, resultan indiferentes las repercusiones de orden psíquico que el agravio originaría en el individuo que lo sufre. Sea que se exprese en dolor, sufrimiento o aflicción, incomodidad u otras penalidades" ${ }^{30}$

Como vemos, nuevamente influye sobre la decisión en torno a la prueba del daño moral el concepto que del mismo se tenga, aunque en este caso -como hemos dicho- se arribe a iguales consecuencias que en el caso anterior que revisamos.

Sea cual sea el concepto de menoscabo no patrimonial adoptado, y a pesar de lo complejo que pueda resultar la prueba de éste, estimamos que no es correcto excluir así sin más, la exigencia probatoria del instituto, por cuanto ello implicaría vulnerar no sólo principios rectores del derecho adjetivo, sino también ir contra los criterios científicos que deben imperar en el desarrollo de una correcta teorización jurídica. ${ }^{31}$

Asimismo, como han señalado acertadamente algunos autores, la eliminación de la carga de la prueba, contribuye a desplazar la mirada en la función de la responsabilidad civil, desde la reparación de los perjuicios y la indemnidad de la víctima, a la punibilidad y castigo del victimario. ${ }^{32}$

\footnotetext{
29 Corral Talciani, Hernán. Lecciones de responsabilidad Extracontractual. Santiago, Chile: Editorial Jurídica de Chile, 2002, p. 166.

30 RDJ, T. LXXXII, secc. 2a, 1985, p. 6.

31 Rodríguez Boente, Sonia. Argumentación fáctica, Los enunciados declarativos de hechos probados. Universidad Santiago de Compostela, Santiago de Compostela, España 2004, p. 373 y ss.

32 González Vergara, Paulina, et al. op. cit. (n. 26), p. 256.
} 
Domínguez Hidalgo, ha prevenido sobre el particular, señalando que acceder a tal exclusión sería abrir la ventana a conductas arbitrarías e injustas, potenciando y dando origen a sentencias disimiles, lo cual en definitiva sería un golpe a la justicia, y a la seguridad jurídica. ${ }^{33}$

3.1.2 Comentarios a la tesis propuesta por la doctrina: Dijimos previamente que la doctrina se encuentra conteste, en torno a la necesidad de probar los perjuicios morales en el proceso judicial.

Así, se ha dicho que el daño moral siempre debe probarse ${ }^{34}$. Y la conclusión no puede ser otra, pues su exigencia arranca ora de principios de orden procesal, ora de orden sustantivo. ${ }^{35}$

\subsubsection{Razones de orden procesal que obligan a probar el daño moral en el proceso}

En efecto, en la esfera del derecho procesal se presentan diversos factores que hacen imperativa la prueba del daño moral en el proceso civil. Dichas exigencias como veremos emanan eminentemente de la propia constitución ${ }^{36}$ y en especial del principio del debido proceso legal.

Y dentro de este principio omnicomprensivo, existen dos aspectos gravitantes que permiten afirmar con soberana seguridad, que la prueba del daño moral, es un imperativo absoluto. Luego, la necesidad de fundamentación de las sentencias que pesa sobre el juez y el derecho a defensa. ${ }^{37}$

Respecto a la necesidad de fundamentación de las sentencias, nuestra Corte Suprema ha señalado "Cuando la prueba se aprecia en conciencia, el fallo debe explicar cómo se llego al resultado probatorio que se resuelve, exigencia que es característica de la llamada valorización por persuasión racional". 38

Sobre ello, se ha pronunciado también autorizada doctrina procesalista, y así se ha dicho que lo jueces se encuentran obligados a justificar sus decisiones y no sólo a explicarlas, lo cual implica que deben dar razones que confieran plausibilidad a estas, de manera que aquello que resuelvan se adecúe a los criterios de la lógica jurídica. ${ }^{39}$

En cuanto al derecho a defensa, dentro del amplio abanico de "derechos" que este envuelve, importa destacar para estos efectos, uno que resulta particularmente gravitante, esto es, el principio de la bilateralidad de la audiencia.

\footnotetext{
33 Domínguez Hidalgo, Carmen. "Aspectos modernos de la reparación por daño moral. Contraste entre el Derecho chileno y el Derecho comparado", en: Revista de Derecho, Universidad Católica del Norte, Coquimbo, 1999, pp. 36 y ss.

34 Domínguez Hidalgo, Carmen, op. cit. (n. 1), p. 153 en la nota al pie (133).

35 González Vergara, Paulina, et al. op. cit. (n. 26), p.258.

36 Nuestra Carta Fundamental en su artículo 19 No 3 señala que toda sentencia de un órgano que ejerza jurisdicción debe fundarse en un proceso previo legalmente tramitado.

37 González Vergara, Paulina, et al. op. cit. (n, 26), p. 261.

38 RDJ, T. LII, secc. $3^{\text {a }}$, p. 51.

39 Tavolari Oliveros, Raúl. Tribunal, Jurisdicción y Proceso. Santiago, Chile: Editorial Jurídica de Chile, 1994, p. 299.
} 
Así, como se ha podido demostrar con las sentencias transcritas, nuestra jurisprudencia cuando no opta por excluir el daño moral, sigue el camino de la presunción del mismo, en cuanto los hechos que han dado lugar a la demanda en el proceso, permitirían suponer la existencia de los mismo ${ }^{40}$. Siendo el caso por antonomasia el de la indemnización del daño por rebote o repercusión.

Luego, esta tesis infringe de forma flagrante el principio de la bilateralidad de la audiencia, y con ello el del debido proceso legal. En efecto, el juez podrá presumir el perjuicio moral, pero para que ello ocurra, el que reclama el perjuicio deberá entregarle los antecedentes probatorios que le permitan deducir la $X$ desconocida, no pudiendo buscarla en antecedentes extra proceso, ni en parangones similares. ${ }^{41}$

En efecto, se encontrará íntimamente relacionado con lo anterior, el hecho de que las partes deben tener la posibilidad de rendir prueba en el proceso que permita desvirtuar una determinada petición realizada por un demandante ante los tribunales de justicia ${ }^{42}$. Resulta lógico por tanto, que el demandado a quien se imputa la comisión de un hecho ilícito que ha ocasionado supuestamente un daño moral, tenga la posibilidad de acreditar que dicha consecuencia jurídica no se ha verificado.

En otra esfera, cabe señalar que el sentenciador se encuentra obligado por imperativa disposición del artículo 160 del Código de Procedimiento Civil, ha fallar conforme al merito del proceso, por lo que apartarse de los antecedentes que obren en el mismo, constituye una infracción de norma, que da origen a recurrir mediante el mecanismo de la casación.

De igual forma como señala la profesora Domínguez Hidalgo -comentando acerca de la obligación de fundamentar las sentencias- "La utilidad de este imperativo resulta evidente: permite situar a la víctima, al responsable y, en su caso, a las aseguradoras en una perspectiva más cierta en materia de resarcimiento". ${ }^{3}$

Ello indudablemente, permite a las partes ejercer sus acciones y excepciones de forma adecuada, exponiéndole al juez los hechos pertinentes para formar su convicción en torno a la procedencia o no de la indemnización por esta partida.

\footnotetext{
40 Verbigracia el caso de la pérdida de un familiar querido, en donde se ha dicho en el fallo del $4^{\circ}$ Juzgado del Crimen de Antofagasta, del 24 de junio de 1985, causa rol No 2.973, en el considerando 21 "Que además es indiscutible que la muerte de un ser querido, provoca para su familia un daño moral, daño que es de indole netamente subjetiva y que queda a la apreciación del juez determinar su monto, atendido el grado de parentesco de quién ha sufrido el daño, con la persona fallecida y las consecuencias naturales producidas".

41 Aedo Barrena, Cristian, op. cit. (n. 28), p. 517.

42 Rodríguez Curutchet, Juan Pablo, op. cit. (n. 21), p. 124.

43 Domínguez Hidalgo, Carmen, op. cit. (n. 1), p. 703.
} 


\subsubsection{Razones de carácter sustantivo que obligan a acreditar el perjuicio no patrimonial}

Fuera del ámbito procesal, se ha dicho que la exigencia de probar la existencia del menoscabo moral es un imperativo del que el juez no puede librar a las partes, pues el daño es un hecho excepcional y por consiguiente de aplicación restrictiva. ${ }^{44}$

En este sentido, se ha negado la existencia de daños morales evidentes, y se han desarrollado un plexo de requisitos que deberían reunirse y ser probados para que el menoscabo moral pueda ser indemnizado, entre los cuales destacan: la legitimación activa; la culpa o el dolo; la relación de causalidad; la capacidad, la existencia efectiva de un daño con características de daño moral; y por algunos las pericias psicológicas si proceden y; la adecuada fundamentación de la ponderación de pruebas indirectas. ${ }^{45}$

Recordemos que la ley sólo en situaciones excepcionales ha llegado a presumir la existencia del daño, como ocurre en los casos de la clausula penal o en el caso del artículo 1559 del Código Civil, cuando sólo se cobran intereses en las obligaciones de dinero ${ }^{46}$. De manera, que para todos los demás casos de daño, sean patrimoniales o extrapatrimoniales, la regla del artículo 1698 relativa a la carga de la prueba, se mantiene completamente vigente en esta materia, debiendo en consecuencia el demandante acreditar sus pretensiones.

Por ello, el mecanismo de la presunción del daño moral, es perfectamente factible, en tanto sean las partes las que proporcionen al juez, los hechos que le permitan a partir de un hecho conocido (el hecho fáctico proporcionado por el actor), arribar a uno desconocido $-y$ pretendido- como lo es, el daño moral que pueda haber sufrido el demandante, conforme se ha expuesto anteriormente.

Esto por lo demás permitiría morigerar las nefastas consecuencias a las que habría de arribar la cuestión, particularmente en materia de indemnización por rebote, por cuanto será necesario acreditar la relación real o el vínculo afectivo verdadero entre la víctima y sus familiares. ${ }^{47}$

Ahora bien, para cuidar la función que el moderno derecho de daños atribuye a la responsabilidad civil, en tanto la mirada y el acento han sido puestos en la victima, atendiendo en consecuencia a su reparación, más que al reproche que habrá de hacerse al victimario, es gravitante hacer notar que lo que se requiere no es una prueba exacta de los perjuicios sufridos por la victima, sino que se proporcionen los medios probatorios suficientes que permitan formar convicción en el sentenciador de que se ha padecido un perjuicio de esa naturaleza. ${ }^{48}$

44 Fueyo Laneri, Fernando. "Capítulo II, La Resarcibilidad del daño moral como tutela de los bienes y derechos de la personalidad”. En su: Instituciones de Derecho Civil Moderno. Santiago, Chile: Editorial Jurídica de Chile, 1990, pp. 106 y ss.

45 Diez Schwerter, Luis, op. cit. (n. 15), p. 146.

46 Aedo Barrena, Cristian, op. cit. (n. 28), p. 507.

47 Sobre el particular véase las sentencias publicadas en: RDJ, T. LXIII, secc. 4ª p. 129; RDJ, T. XLIV, secc. 1ª, p. 130.

48 Zavala De González, Matilde. Resarcimiento de Daños. Buenos Aires, Argentina: Editorial Hammurabi, 1996, p. 565. 
En consecuencia se trata de que el juez al momento de apreciar y valorar la prueba flexibilice su labor, lo cual es completamente diferente a señalar que él tenga facultades para excluir la prueba del daño moral o para presumirlo sin más antecedentes ${ }^{49}$. Pues como señala un autor, "no existe otro país, al menos en lo que se ha podido constatar, que establezca un principio así de entrada y ello es evidente pues, si el objeto de la responsabilidad civil es la reparación -de forma casi exclusiva en el presente- se comprenderá que es imprescindible que la existencia del daño se acreditada". 50

\subsection{MEdios PROBATORIOS QUE PERMITEN ACREDITAR EL MENOSCABO EXTRAPATRIMONIAL:}

Finalmente, es oportuno, hacer notar que respecto a los medios idóneos para probar el daño moral, una vez más, como ya se ha dicho majaderamente, el concepto que se tenga de daño moral, influirá decisivamente en la materia.

Eso sí, lo que resulta claro, es la necesidad que tiene la victima de aportar los antecedentes necesarios para que el juez pueda formar su convicción respecto la procedencia del daño moral. Para lo cual, al no existir una regla especial que limite los medios probatorios para este tipo de daños, caben todos aquellos señalados por la ley. ${ }^{51}$

En este estado de cosas, las partes podrán valerse para acreditar la procedencia -o no procedencia- del daño moral invocado por una de ellas, de la prueba documental, pericial, testifical, y la prueba en base a presunciones.

En cuanto a la prueba documental, esta será de gran ayuda, por ejemplo, para el caso acreditar lesiones corporales, en el caso de los informes médicos o bien con medios fotográficos y así lo ha señalado la jurisprudencia ${ }^{52}$. Igualmente servirá para acreditar daño moral en los casos de indemnización de victimas por rebote, mediante las partidas de nacimiento o matrimonio, que acrediten la relación de parentesco o el estado civil de casado o viudo de la víctima.

Respecto la prueba testifical, su utilidad como medio probatorio para acreditar esta partida, queda demostrado en la sentencia de la Ilustrísima Corte de Apelaciones de Santiago de 15 de julio del año 1997, que en su considerando sexto señala: "El daño moral ha quedado establecido con los testimonios del médico neurólogo y con la ficha clinica y demás antecedentes del tratamiento médico, en cuanto al sufrimiento soportado y afección psicológica del actor". 53

\footnotetext{
Corral Talciani, Hernán, op. cit. (n. 29), p.164.

Domínguez Hidalgo, Carmen, op. cit. (n.33), p. 326.

Rodríguez Curutchet, Juan Pablo, op. cit (n. 21), p. 129.

RDJ, Tomo 65, secc., p. 241; G.J 2002, N² 270, p. 183.

G.J 1997, N²05, p. 174.
} 
Igualmente del fallo del mismo Tribunal, de fecha 28 de enero del año 1993, que en sus considerandos decimo tercero y decimo cuarto señalan:

"Que finalmente respecto del daño moral demandado, que se hace consistir en las molestias que el actor ha debido sufrir por la poliaquiuria y que le ha impedido dormir y llevar una vida medianamente normal (...) y que según los testimonios de (...) quienes sostienen en sintesis que a concurrencia de la lesión sufrida por el actor, causada en el trastorno de la operación que se le practicó y que se ha traducido en una persistente poliaquiuria, éste ha padecido de un gran dolor psiquico, que lo ha transformado en una persona cansada, amarga, quejumbrosa, trastornando de su modo de vivir anterior (...) El Tribunal dada la entidad del daño moral infringido al actor, de que dan cuenta los dichos de los testigos referidos (...)".54

Para el caso del informe de peritos, las pericias de carácter psicológico pueden servir para acreditar la intensidad el daño ${ }^{55}$. Asimismo, proporcionarán una importante herramienta al sentenciador para efectos de la valoración del daño moral. Los informes evacuados por profesionales médicos, son sustanciales a la hora de definir el daño moral como pretium doloris, por cuanto permitirán formarse una idea más o menos clara de cuál es el real estado psicológico de una víctima. En todo caso, valga la advertencia de que los informes periciales, en general, son simplemente ilustrativos, que tienen el valor probatorio de las personas designadas y por eso su valor probatorio se aprecia conforme a las reglas de la sana crítica. ${ }^{56}$

Finalmente la prueba basada en presunciones, es sin lugar a dudas una herramienta probatoria importante al momento de acreditar el daño moral. Ahora, como hemos indicado anteriormente, es imperativo que las partes proporcionen los antecedentes necesarios al sentenciador, que le permitan a través de hechos conocidos y probados, arribar a otros desconocidos que se han de presumir. El juez, podrá perfectamente utilizar este medio probatorio respetando el silogismo básico que su utilización presupone, en donde la premisa mayor estará constituida por el hecho ilícito, la premisa menor por todos los antecedentes que permiten acreditar que efectivamente se ha padecido un daño moral, y la conclusión que será en definitiva la existencia del daño moral.

Como ha sido graficado, la premisa mayor estará constituida por los lazos familiares, o por la pérdida de un miembro, el menoscabo al honor u otro interés, premisa que es obtenida mediante un razonamiento inductivo. Por otro lado la conclusión será el daño moral, de manera que los jueces no pueden unir la premisa mayor a la conclusión inmediatamente, porque suponen que la pérdida de un familiar o un miembro provoca un perjuicio no patrimonial, antes por el contrario deberán elaborar la premisa menor, constituida por todos aquellos antecedentes de los que puede deducirse mediante un proceso racional de apreciación probatoria, la existencia efectiva del daño moral en cuestión. ${ }^{57}$

54 G.J 1993, No 151, p. 55.

55 Barros Bourie, Enrique, op. cit. (n. 2), p. 333.

56 Diez Duarte, Raúl. De la prueba del contrato. Santiago, Chile: Editorial Jurídica Conosur Ltda, 1997, p. 174.

57 Aedo Barrena, Cristian, op. cit. (n. 28), p. 516. 
No huelga señalar que para que las presunciones puedan tener valor como medio probatorio, es imperativo que cumplan con los requisitos de los artículos 1712 del Código Civil y 426 del Código de Procedimiento Civil, en el sentido que deben ser graves, precisas y concordantes.

\section{CONCLUSIONES}

Como en casi todo el desarrollo de la teoría de la responsabilidad, el asunto de la prueba del daño moral, constituye un árido desierto, en donde las discrepancias se han erigido como soberanas entre la doctrina y la jurisprudencia.

Empero, como en pocas instituciones del derecho de daños, la doctrina nacional ha podido encontrar un espacio común, en torno a aceptar la necesidad de la prueba del daño moral en los procesos judiciales.

Por su parte la jurisprudencia, ha sido vacilante en la materia, pero mayoritariamente se ha pronunciado negando la necesidad de prueba, o simplificando el asunto a la esfera de las presunciones, pero adoptando un criterio que creemos es errado, por cuanto ha elaborado una presunción de derecho al respecto o más bien una ficción de existencia del daño moral, que en la práctica no admite prueba en contrario.

Por ello, como acertadamente ha dicho la doctrina, el criterio adecuado que se debe seguir es el de elaborar, un sistema de prueba del instituto, que no altere uno de los principios rectores de la responsabilidad civil, como lo es, la protección e indemnidad de la víctima, o el principio de reparación integral de la víctima, pero que tampoco menoscabe la construcción científica del ordenamiento jurídico, introduciendo alteraciones en sus cimientos, como lo es, verbigracia la vulneración a los principios del debido proceso, la regulación de la apreciación de la prueba, o obligación de fundamentación de las sentencias del juez.

De manera tal, que los esfuerzos deberán estar encaminados a uniformar los conceptos previos a la prueba del menoscabo moral, precisando los contornos exactos de que debe entenderse por daño moral, para luego ir avanzado en resolver los problemas pendientes en la materia.

Es tarea de los juristas, encontrar equilibrio y diseñar las diversas disciplinas que comprenden la enciclopedia jurídica, haciéndolas coherentes y acordes con los principios jurídicos que inspiran todo el sistema. Por ello, será imperativo acercar los conceptos doctrinarios a los jurisprudenciales e integrar estos a los primeros, sólo de esta manera será posible abrazar el ideal de justicia que nos guía, respetando la bases científicas que nos han permitido alzarnos hacía el. 


\section{REFERENCIAS BIBLIOGRÁFICAS}

Abeliuk Manasevich, René. Las Obligaciones, Tomo I -4a Edición- Santiago, Chile: Editorial Jurídica de Chile, 2001.

Aedo Barrena, Cristian. Responsabilidad Extracontractual. Santiago, Chile: Librotecnia, 2006.

"El daño moral: Concepto, prueba y valoración en la doctrina y jurisprudencia Chilena", en: Revista de Ciencias Jurídicas de la Universidad Católica del Norte, Tomo IV, Antofagasta, 2005.

Alessandri rodríguez, Arturo. Responsabilidad civil extracontractual en el Derecho Civil Chileno. Tomo I -2da edición-Santiago, Chile: Editorial Jurídica Conosur, 1998.

Barros Bourie, Enrique. Tratado de Responsabilidad Extracontractual. Santiago, Chile: Editorial Jurídica de Chile, 2006.

Corral talciani, Hernán. Lecciones de responsabilidad Extracontractual. Santiago, Chile: Editorial Jurídica de Chile, 2002.

Diez schwerter, José Luis. El Daño Extracontractual. Jurisprudencia y doctrina -1a edición- Santiago, Chile: Editorial Jurídica de Chile, 1997.

Diez Duarte, Raúl. De la prueba del contrato. Santiago, Chile: Editorial Jurídica Conosur Ltda, 1997.

Domínguez hidalgo, Carmen. "Aspectos modernos de la reparación por daño moral. Contraste entre el Derecho chileno y el Derecho comparado", en: Revista de Derecho, Universidad Católica del Norte, Coquimbo, 1999.

. El daño Moral. Santiago, Chile: Editorial Jurídica de Chile, 2002.

. "El Daño Moral en Chile Contornos y Problemas", en: Revista Anales de Derecho UC, Temas de Responsabilidad Civil, Santiago, Chile, vol. 1, 2006.

Fueyo laneri, Fernando. "Capítulo II, La Resarcibilidad del daño moral como tutela de los bienes y derechos de la personalidad". En su: Instituciones de Derecho Civil Moderno. Santiago, Chile: Editorial Jurídica de Chile, 1990.

González Vergara, Paulina y Cárdenas Villareal, Hugo. Sobre la prueba de la existencia del daño moral. En: Jornadas Chilenas de Derecho Civil: Estudios de derecho civil II: código civil y principios generales : nuevos problemas, nuevas soluciones. Santiago, Chile: Lexis Nexis, 2007.

Mazeaud, Henri, et al. Tratado teórico y práctico de la responsabilidad civil delictual y contractual -1a edición- Traducción de la $5^{\circ}$ edición francesa por Santiago Sentís Melendo. Buenos Aires, Argentina: Ediciones Jurídicas Europa-América, 1977.

Meza barros, Ramón. Manual de derecho civil: De las fuentes de las obligaciones, Tomo II -8a edición- Santiago, Chile: Editorial Jurídica de Chile. Colección de Manuales Jurídicos, 1992.

Mosset Iturraspe, Jorge y Novellino, Norberto. Derecho de Daños. La prueba en el proceso de daños. Buenos Aires, Argentina: Ediciones La Rocca, 1996.

Ochoa Olivera, Salvador. La demanda por daño moral. Atizapán de Zaragoza, España: Montealto Editores, 1999.

Pavlovic Jeldres, Karim, La indemnización que debe corresponder de acuerdo a nuestro derecho, por los perjuicios derivados del daño moral. Tesis (Licenciado en Ciencia Jurídicas). Santiago, Chile: Pontificia Universidad Católica de Chile, 1999.

Pérez Fuentes, Gisela. "El derecho de daños en México", en: Revista Anales de Derecho UC, Temas de responsabilidad Civil, Santiago, Chile, vol. 1, 2006.

Pizarro, Ramón. Daño moral. Prevención. Reparación. Punición-1a edición- Buenos Aires, Argentina: Hammurabi, 2000.

Ramos Pazos, René. De las Obligaciones. Santiago, Chile: Lexis Nexis, 2004. 
Rodríguez Boente, Sonia. Argumentación fáctica, Los enunciados declarativos de hechos probados. Universidad Santiago de Compostela, 2004.

Rodríguez Curutchet, Juan Pablo. La evaluación y prueba del daño moral en la jurisprudencia Nacional. Tesis (Licenciado en Derecho), Santiago, Chile: Pontificia Universidad Católica de Chile, 2007.

Rodríguez Grez, Pablo. Responsabilidad Extracontractual. Santiago, Chile: Editorial Jurídica de Chile, 1999.

Tavolari oliveros, Raúl. Tribunal, Jurisdicción y Proceso. Santiago, Chile: Editorial Jurídica de Chile, 1994.

Zannoni, Eduardo. El daño en la responsabilidad civil. Buenos Aires, Argentina: Astrea, 1987.

Zavala De González, Matilde. Resarcimiento de Daños. Buenos Aires, Argentina: Editorial Hammurabi, 1996. 